\title{
Interconnection of a Wind Driven DC Machine with the Power Utilities Grid
}

\author{
Maamar Taleb*
}

\author{
University of Bahrain, Department of Electrical and Electronics Engineering, P.O. Box 32038, ISA Town - \\ Bahrain
}

\begin{abstract}
A wind driven DC machine is interconnected with the power utilities grid. The wind driven DC machine is operated in the regenerative mode and that is to guaranty the extraction of the real power from the wind driven generator and inject it into the power grid. This is done through the use of a single phase full wave controlled converter operating in " an inverter mode of operation". At any pretended surrounding weather conditions, maximum extraction of power from the renewable energy source (ie. Wind energy source) is targeted. This is done through the realization of a self-adjusted firing angle controller responsible of triggering the semiconductor elements of the controlled converter. An active power filter is shunted with the proposed setup to guaranty the sinusoid quality of the power utilities line current. The overall performance of the proposed system has been simulated in MATLAB/SIMULINK environment. Quite satisfactory and encouraging results have been obtained.
\end{abstract}

Keywords: Integration of Renewable Energy Sources with Grid Systems, Wind Driven DC Machine, Maximum Power Point Tracker, Active Power Filter, MATLAB/SIMULINK Applications.

\section{INTRODUCTION}

It is well known that most (if not all) renewable energy resources suffer from the lack of providing constant power. This is due to the uncontrollable change of the surrounding weather and environmental conditions. A possible and practical solution to overcome the problem of relying on the power generated by the renewable energy resources is to constitute a hybrid DC grid made of a combination of parallel renewable energy resources and storage units and interconnect it (i.e the hybrid DC grid) to the $A C$ grid [1-3]. The DC grid is usually linked to the $A C$ grid through conventional power inverter modules [1-3].

The present paper uses a different power inverter circuit topology. It consists of using a single phase full wave controlled converter operating in the "inverter mode of operation". This type of inverter was used by the author in the work reported in reference [4]. The work done in the present article consists of connecting a separately excited DC machine to the power grid through a cascaded setup consisting of a single phase full wave controlled converter/rectifier and a smoothing reactor. The DC machine is driven by a wind turbine "as a prime mover " and it is operated in the "regenerative mode". To avoid the penetration of the harmonic currents generated by the controlled converter into the power grid, an active power filter is

*Address correspondence to this author at the University of Bahrain, Department of Electrical and Electronics Engineering, P.O. Box 32038, ISA Town - Bahrain; Tel: +973 39151520; Fax: +973 17680924;

E-mail: mtaleb@uob.edu.bh shunted with the proposed circuit configuration. The used active power filter is a kind of a voltage source inverter [5]. Its operation is controlled by a PWM technique that is in turns controlled or monitored by a certain hysteresis controller.

To extract the maximum power from the wind driven DC machine at any surrounding wind speed level, a maximum power point tracker is added to the proposed interconnection configuration. The maximum power point tracker performs its task by updating online the firing pulses needed by the semiconductor valves of the single phase full wave controlled converter.

The proposed interconnection topology owns the following merits when compared to their counterparts in the conventional ways of interconnection [1-3]:

No need to worry about the synchronization with the AC power utilities grid.

- No need to worry about the level of the generated DC generator voltage. The smoothing reactor allocated at the $\mathrm{DC}$ side of the converter takes care about any voltage differences.

No worry about the harmonic currents generated from the proposed configuration. The existence of active power filter will cancel such harmonics and will prevent them from spreading out into the power utilities grid.

No need to storage units (i.e batteries).

The present work differs from the work done by the author in reference [4] in the next two aspects: 
The type of electric generator used in the DC side of the controlled converter. Reference [4] used a permanent magnet $A C$ generator whose output voltage needs to be rectified using a single phase full wave uncontrolled bridge rectifier. Present work uses a simple separately excited DC generator.

No actions, concerning the harmonic currents generated by the controlled converter, have been considered in reference [4]. Present work takes care of the undesired harmonics by installing a shunt active power filter.

The present works can be considered as an extension to the work of reference [4].

\section{STUDY SYSTEM}

A general scheme of the study system is presented in Figure 1. The figure consists of three parts: a wind driven DC machine setup operated by a controlled single phase full wave bridge rectifier, an AC voltage source representing the power utilities side or the grid, and an active power filter. The desired powers flow and the current directions are simplified by the arrows direction. The full wave converter as well as the active power filter modules are controlled by an external selftuning controllers. The voltage polarity of the DC machine is reversed in the figure and that is to indicate that the machine will be generating power rather than absorbing power.

Figure 2 details the contents of Figure 1. The controller needed to generate the convenient pulses to trigger the thyristors of the bridge converter as well as the one needed to generate pulses to drive the gates of the IGBT's of the active power filter module are shown in the figure (i.e Figure 2).

The next subsections describe the mathematical model and the operation of the important blocks of Figure 2.

\subsection{Generated Wind Power}

The power of the moving air through a wind rotor can be expressed as [6]:

$P_{o}=\frac{1}{2} A_{r} \rho V_{w}^{3}$

where

$\mathbf{A}_{\mathrm{r}}$ represents the swept area by the motor rotor and it is set to $A_{r}=\pi r^{2}$.

$\mathbf{r}$ represents the radius of the rotor of the wind turbine.

$\rho$ density of the air which may be taken at normal temperature and pressure as equals to $1.25 \mathrm{~kg} / \mathrm{m}^{3}$

$\mathbf{V}_{\mathbf{w}}$ is the wind speed in meter/second $(\mathrm{m} / \mathrm{s})$.

The moving air power $\left(\mathbf{P}_{\mathbf{o}}\right)$ can be converted partially to a mechanical power. The mechanical power that can be extracted from such moving air power can be expressed as [6]:

$P_{w}=C_{p} P_{o}$

The moving air power $\left(\mathbf{P}_{\mathbf{o}}\right)$ can be converted partially to a mechanical power. The mechanical power that can be extracted from such moving air power can be expressed as [6]:

$P_{w}=C_{p} P_{o}$

$\mathbf{C}_{p}$ is a dimensionless performance power coefficient and its value is naturally always $<1$. Investigator of reference [6] proposed a handy formula for $\mathrm{Cp}$ in the form of:

$C_{p}=C_{1}\left(C_{2}-C_{3} p-C_{4} p^{x}-C_{5}\right) e^{-C_{6}}$

Where $\mathrm{C}_{1}=0.5, \mathrm{C}_{2}=116 / \lambda_{\mathrm{i}}, \mathrm{C}_{3}=0.4, \mathrm{C}_{4}=0 ., \mathrm{C}_{5}=5$, $\mathrm{C}_{6}=21 / \lambda_{\mathrm{i}}, \mathrm{x}=1.5$.

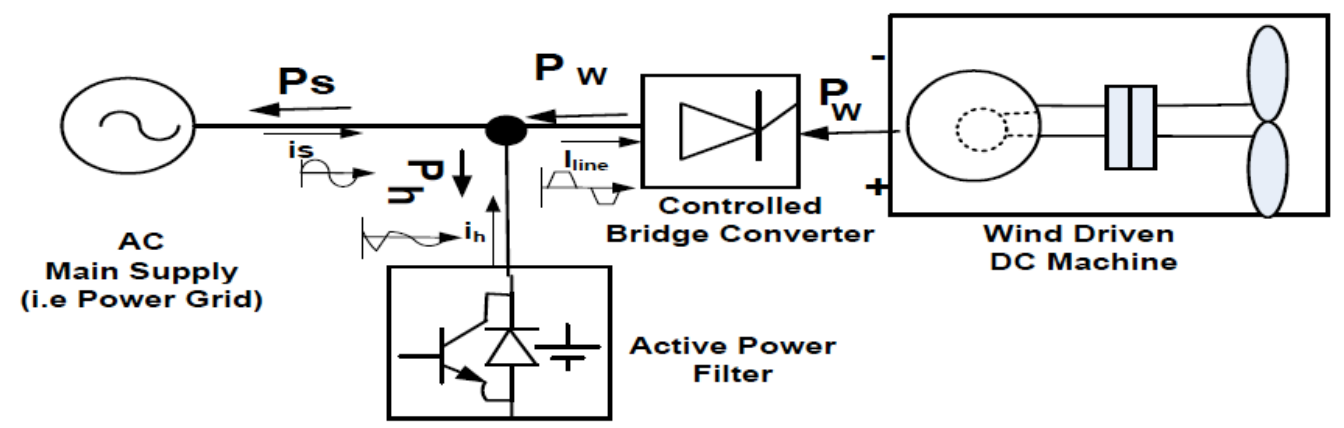

Figure 1: Study System. 


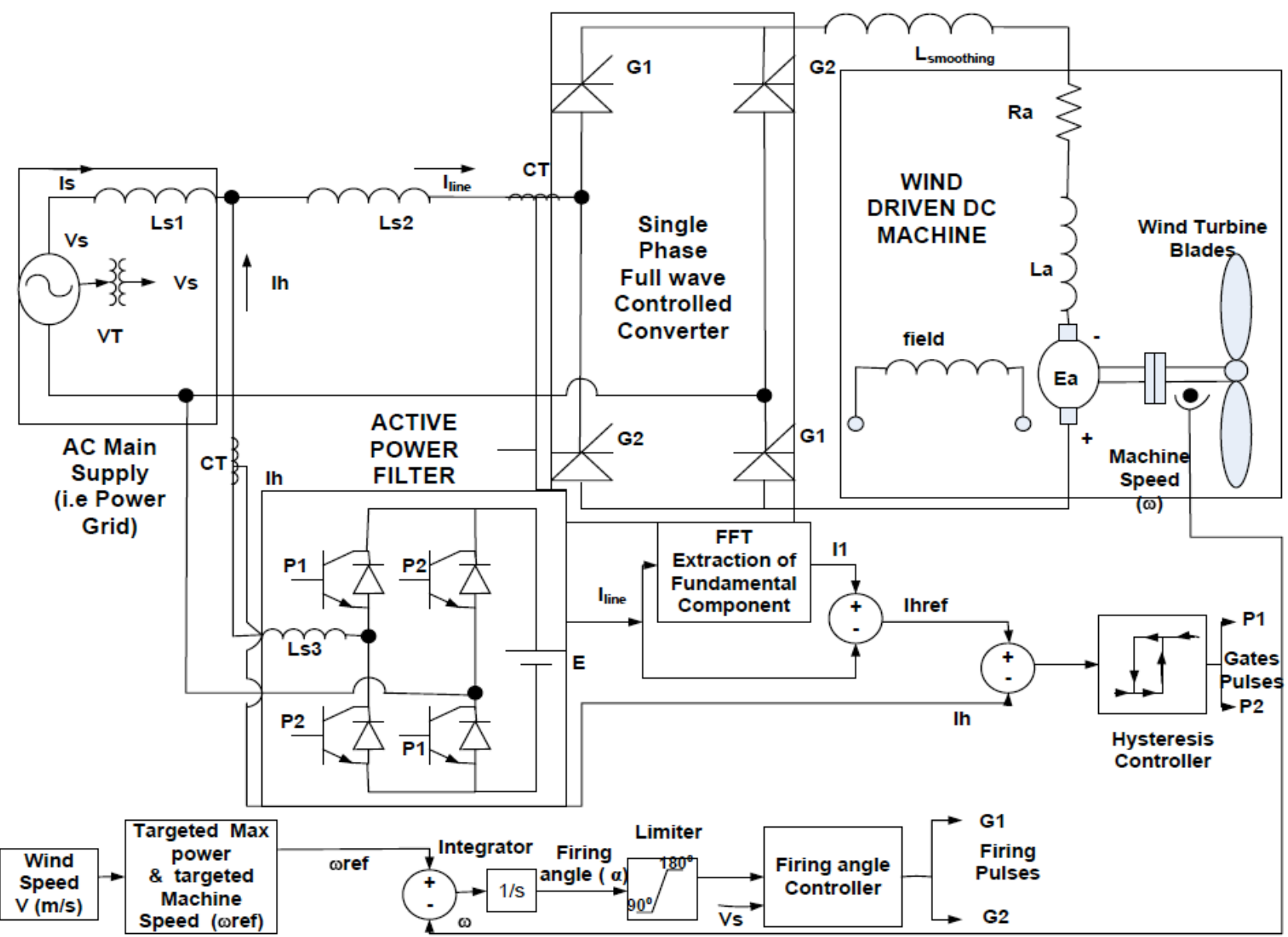

Figure 2: Detailed Circuitry of the Study System.

$\frac{1}{\lambda_{i}}=\frac{1}{\lambda+0.08 p}-\frac{0.035}{p^{3}+1}$ and $\lambda=\frac{r \omega_{w}}{V_{w}}$

p: pitch angle between the blade element with respect to the plane of rotation. The

$\lambda$ is known as the tip speed ratio.

$\mathbf{C}_{\mathrm{p}}$ is maximized when the tip speed ratio $\lambda$ is equal to 7.975340822. The corresponding value of the coefficient $\mathrm{C}_{\mathrm{p}}$ at such tip speed ratio is $\mathbf{C}_{\mathrm{p}, \max }=$ 0.413814988 . The previous numbers are found from the derivation done by the author in the appendix of reference [7].

The maximum extracted power from the wind turbine is of the form:

$P_{w, \max }=\frac{1}{2} A_{r} \rho V_{w}^{3} C_{p, \max }=\frac{0.413814988}{2} A_{r} \rho V_{w}^{3}$

Thus, for the sake of extracting maximum wind power $\left(P_{w, \max }\right)$ at a certain wind speed $\left(V_{w}\right)$, the wind driven DC machine speed has to be controlled by the firing angle controller block of Figure 2 and made to be rotating at the following angular velocity:

$\omega_{r e f}=\frac{7.975340822 V_{w}}{r}$

The separately excited DC machine is represented by a series combination of the armature resistance $(\mathrm{Ra})$, the armature inductance (La), and the internal generated voltage (Ea). Ea (output voltage) is proportional to the machine speed $(\omega)$ and the field flux $(\phi)$. The field flux is kept constant in this study.

\subsection{Controlled Converter}

The controlled converter is no more than a controlled single phase full wave bridge rectifier. The rectifier is operated in a mode termed "Inverter Mode of Operation". In a such mode of operation, the firing angle provided to the SCRs valves of the bridge should be greater than $90^{\circ}$. The average value of the voltage at the dc side of the bridge rectifiers will be obeying the following expression: 


$$
V_{D C}=K_{1} \cos (\alpha)
$$

Where $\mathbf{K}_{\mathbf{1}}$ is a positive constant and it is proportional to the RMS value of the main AC supply voltage and $\alpha$ represents the firing angle.

For any value of the firing angle greater than $90^{\circ}$, the average voltage $V_{D C}$ is negative. A negative value of the voltage $V_{D C}$ times a positive value of the current that circulates in the smoothing reactor, located at the DC side of the converter, results in a negative value for the power at the DC side of the controlled converter/bridge rectifier. That leads to the statement that such power is generated by the wind driven DC machine and it is injected into the $A C$ side of the Converter. In other words, the DC machine is operated in the regenerative mode.

As to the way of generating or controlling the firing angle of the bridge rectifier, the measured machine speed $(\omega)$ is subtracted from a reference speed $\left(\omega_{\text {ref }}\right)$, $\omega_{\text {ref }}$ is calculated at each wind speed using equation (5), to give an error that will be integrated to give an updated value of the firing angle ( $\alpha$ ). The firing angle value is limited between $90^{\circ}$ and $180^{\circ}$ to guaranty the regeneration mode of the DC machine. Under steady state conditions, the machine speed $(\omega)$ will get close to the reference speed $\left(\omega_{\text {ref }}\right)$. In satisfying such conditions, the maximum wind power is extracted from the wind turbine/prime mover. Therefore, it can said or deduced that the intended task from the firing angle controller is to play the role of a maximum power point tracker.

\subsection{Active Power Filter}

The use of the controlled single phase full wave bridge rectifier alone results in the distortion of the line current (l line). The distortion of the line current will generate harmonic currents. Such harmonic currents penetrate into the power grid and causes undesirable effects. Therefore, it is necessary that a shunt filter should be allocated at the point of interconnection found between the power utilities grid and the controlled converter. The active power filter proposed in reference [5] is one of the solutions to the problem of undesired generated harmonic currents. The used active power filter is a voltage source inverter, as shown in the left bottom side of Figure 2. The active power filter performs its tasks as follows:

a reference signal $\left(I_{\text {href }}\right)$ is generated or calculated online. It consists of the difference between the fundamental component of line current $\left(l_{\text {line }}\right)$ entering the bridge rectifier and the line current (l line $)$ itself.

a measured current (Ih) located at the AC side of the bridge inverter is subtracted from the previous reference signal (Ihref).

the result of the previous subtraction is fed to a hysteresis controller. The output of the hysteresis controller is high or low and it is passed to the gates of the IGBTs having the attributions (P1) in Figure 2. The signal passed to the gates of the IGBTs having the attributions (P2) in Figure 2 is the just the complementary of the output signal obtained from the hysteresis controller.

- $\quad$ under steady state conditions, the current (Ih) at the $A C$ side of the bridge inverter is nearly equal to:

$I_{h}=i_{1}-I_{\text {line }}=I_{\text {href }}$

where $\mathbf{i}_{1}$ is the fundamental component of the line current ( $\mathbf{I}_{\text {line }}$ ) entering the AC side of the converter.

Applying Kirchhoff's current law, at the point of the connection of the active power filter, results that the current drawn from the power grid is:

$I s=i_{1}$

Thus, the supply current will be free from harmonic currents/components. This means that the active power filter does its duty as intended to do so.

\section{SYSTEM PERFORMANCE}

The performance of the proposed interconnection of Figure 2 has been evaluated using computer simulations. MATLAB/SIMULINK has been used. The system data used in the simulations are provided in Table 1.

For certain pretended wind speeds, the performance looked for consists of:

recording continuously the maximum power that can be extracted from the wind turbine, the power delivered by the DC machine, and the power delivered to the $\mathrm{AC}$ voltage supply/ power utilities grid,

recording continuously the reference and the actual/measured speeds of the DC machine, 
Table 1: System Data

\begin{tabular}{|c|c|c|c|c|c|c|}
\hline \multicolumn{7}{|c|}{ DC Machine } \\
\hline $\begin{array}{c}\text { Armature } \\
\text { resistance } \\
\mathrm{Ra}=0.4832 \Omega\end{array}$ & $\begin{array}{c}\text { Armature } \\
\text { inductance } \\
\mathrm{La}=6.763 \mathrm{mH}\end{array}$ & $\begin{array}{c}\text { Field } \\
\text { resistance } \\
\mathrm{Rf}=220 \Omega\end{array}$ & $\begin{array}{c}\text { Field inductance } \\
\qquad \mathrm{Lf}=110 \mathrm{H}\end{array}$ & $\begin{array}{l}\text { Field Voltage } \\
\qquad f=220 \mathrm{~V}\end{array}$ & $\begin{array}{l}\text { Moment of Inertia } \\
\mathrm{J}=0.2053 \mathrm{~kg} \cdot \mathrm{m}^{2}\end{array}$ & $\begin{array}{c}\text { Field-Armature } \\
\text { Mutual Inductance } \\
\text { Laf }=\mathrm{K} \phi=1 \mathrm{H}\end{array}$ \\
\hline \multicolumn{7}{|c|}{ Wind Turbine } \\
\hline \multicolumn{7}{|c|}{ Blades length $(r)=120 \mathrm{~cm}$} \\
\hline \multicolumn{7}{|c|}{ DC smoothing Coil Inductance $0.5 \mathrm{H}$} \\
\hline \multicolumn{7}{|c|}{ AC Main Supply } \\
\hline \multicolumn{2}{|c|}{$\begin{array}{l}\text { Rms Voltage } \\
240 \mathrm{~V}\end{array}$} & \multirow[t]{2}{*}{$\begin{array}{l}\text { Frequency } \\
50 \mathrm{~Hz}\end{array}$} & \multicolumn{2}{|c|}{$\begin{array}{l}\text { Phase angle } \\
0^{0}\end{array}$} & \multicolumn{2}{|c|}{$\begin{array}{c}\text { Leakage inductance } \\
\text { Ls1 }=2.5 \mathrm{mH}, \mathrm{Ls} 2=2.5 \mathrm{mH}\end{array}$} \\
\hline \multicolumn{6}{|c|}{ Active Power Filter } & \\
\hline \multicolumn{2}{|c|}{$\begin{array}{l}\text { DC Voltage source } \\
\qquad E=400 \mathrm{~V}\end{array}$} & \multicolumn{3}{|c|}{$\begin{array}{l}\text { Leakage inductance } \\
\qquad \text { Ls3 }=5 \mathrm{mH}\end{array}$} & \multicolumn{2}{|c|}{$\begin{array}{l}\text { Hysteresis controller } \\
\text { Current Band } 0.04 \mathrm{~A}\end{array}$} \\
\hline
\end{tabular}

- $\quad$ recording continuously the updated value of the firing angle,

- calculating continuously the total harmonic distortion factor (THD) in the supply current

- $\quad$ calculating continuously the displacement power factor at the supply side bus,

recording continuously the time-varying waveforms of: the supply current, the current entering the bridge converter, the current supplied by the active power filter and the reference/desired current of the active power filter.

The previous performance is done once with the existence of the shunt active power filter and another time without the existence of the shunt active power filter. Table 2 depicts the steady state values of the powers performance.
Table 3 reports the desired and measured machine speeds, the total harmonic distortion factor in the supply current, and the displacement power factor at the power utilities side.

A glance at the second and the third columns of Table 2 as well as at the sixth and the seventh columns of Table $\mathbf{2}$, one can clearly notice that nearly maximum power is extracted from the wind turbines at any pretended wind speed. Thus, it can be said the firing angle controller of Figure 2 is performing the role of the maximum power point tracker. The tracker keeps updating automatically its firing angle value as the wind speed changes. The differences between the extracted power from the wind turbine (i.e column 3 of Table 2) and the power delivered to the power utilities (i.e column 4 of Table 2) consist of the power losses in the armature resistance $\left(R_{a}\right)$ of the $D C$ machine. The same previous statement holds for the differences between the powers of columns 7 and 8 of Table 2 .

Table 2: Steady State Powers Results

\begin{tabular}{|c|c|c|c|c|c|c|c|c|}
\hline \multirow[b]{2}{*}{$\begin{array}{c}\text { Wind } \\
\text { Speed } \\
V_{\mathrm{w}}(\mathrm{m} / \mathrm{s})\end{array}$} & \multicolumn{4}{|c|}{ With the use of the active power filter } & \multicolumn{4}{|c|}{ Without the use of the active power filter } \\
\hline & $\begin{array}{l}\text { Targeted } \\
\text { Maximum } \\
\text { Wind } \\
\text { Generator } \\
\text { Power (W) }\end{array}$ & $\begin{array}{l}\text { Extracted } \\
\text { Power from } \\
\text { the Wind } \\
\text { Turbine } \\
\text { (W) }\end{array}$ & $\begin{array}{l}\text { Power } \\
\text { Delivered to } \\
\text { the power } \\
\text { Utilities } \\
\text { (W) }\end{array}$ & $\begin{array}{l}\text { Power } \\
\text { consumed } \\
\text { by the } \\
\text { active } \\
\text { power Filter } \\
\text { (W) }\end{array}$ & $\begin{array}{l}\text { Targeted } \\
\text { Maximum } \\
\text { Wind } \\
\text { Generator } \\
\text { Power (W) }\end{array}$ & $\begin{array}{l}\text { Extracted } \\
\text { Power from } \\
\text { the Wind } \\
\text { Turbine } \\
\text { (W) }\end{array}$ & $\begin{array}{l}\text { Power } \\
\text { Delivered to } \\
\text { the power } \\
\text { Utilities } \\
\text { (W) }\end{array}$ & $\begin{array}{c}\text { Power } \\
\text { consumed } \\
\text { by the } \\
\text { active } \\
\text { power } \\
\text { Filter (W) }\end{array}$ \\
\hline 3 & 31.5909 & 31.3456 & 28.6799 & 0.2012 & 31.5909 & 31.2299 & 28.7805 & - \\
\hline 4 & 74.8822 & 74.4446 & 71.1959 & 0.3398 & 74.8822 & 74.2296 & 71.3383 & - \\
\hline 5 & 146.2543 & 145.2972 & 140.6440 & 0.0146 & 146.2543 & 141.1600 & 136.6013 & - \\
\hline 6 & 252.7274 & 252.1911 & 249.8794 & 5.8205 & 252.7274 & 248.7021 & 241.4950 & - \\
\hline
\end{tabular}


Table 3: Other Steady-State Results

\begin{tabular}{|c|c|c|c|c|c|c|c|c|}
\hline \multirow{2}{*}{$\begin{array}{l}\text { Wind } \\
\text { Speed } \\
V_{w} \\
(\mathrm{~m} / \mathrm{s})\end{array}$} & \multicolumn{4}{|c|}{ With the use of the active power filter } & \multicolumn{4}{|c|}{ Without the use of the active power filter } \\
\hline & $\begin{array}{l}\text { Desired } \\
\text { Machine } \\
\text { speed } \\
(\text { rpm) }\end{array}$ & $\begin{array}{l}\text { Measured } \\
\text { Machine } \\
\text { Speed (rpm) }\end{array}$ & $\begin{array}{c}\text { Total } \\
\text { Harmonic } \\
\text { Distortion } \\
\text { Factor } \\
\text { (THD) } \\
\%\end{array}$ & $\begin{array}{l}\text { Displacement } \\
\text { Power Factor }\end{array}$ & $\begin{array}{c}\text { Desired } \\
\text { Machine } \\
\text { speed (rpm) }\end{array}$ & $\begin{array}{l}\text { Measured } \\
\text { Machine } \\
\text { Speed (rpm) }\end{array}$ & $\begin{array}{c}\text { Total } \\
\text { Harmonic } \\
\text { Distortion } \\
\text { Factor } \\
\text { (THD) } \\
\%\end{array}$ & $\begin{array}{l}\text { Displacement } \\
\text { Power Factor }\end{array}$ \\
\hline 3 & 951.96 & 952.16 & 3.0610 & -0.3095 & 951.96 & 952.20 & 46.1691 & --0.3106 \\
\hline 4 & 1264.3 & 1269.2 & 1.7435 & -0.4388 & 1264.3 & 1269.2 & 25.1017 & -0.4403 \\
\hline 5 & 1587.1 & 1587.5 & 1.2143 & -0.6075 & 1587.1 & 1588.5 & 11.1524 & -0.6031 \\
\hline 6 & 1904.1 & 1907.9 & 1.3959 & -0.8178 & 1904.1 & 1903.1 & 31.2421 & -0.8406 \\
\hline
\end{tabular}

The fifth column of Table 2 indicates the amount of powers consumed by the shunt active power filter. Such powers are measued at the power utilities bus. As can be noted, the levels of such powers are very small because the active power filter relies on getting its power from the DC battery located at the DC side of the voltage source inverter rather than from the power utilities supply.

An another indirect way to deduce also that the firing angle controller of Figure $\mathbf{2}$ is performing the role of a maximum power point tracker is to examine the measurements reported in columns 2 and 3 of Table 3 or the ones reported in columns 6 and 7 of Table 3 . At any pretended wind speed, The DC machine speeds settle down near the desired reference speeds. Driving the machine near the desired reference speeds will certainly guaranty the extraction of maximum powers from the wind turbine.

The negative signs in the displacement power factors reported in columns 5 and 9 of Table 3 should not cause a surprise. The angle between the power utilities voltage and fundamental component of the supply current is expected to be greater than $90^{\circ}$. Such angle is indirectly related to the firing angle $(\alpha)$ value of the bridge converter. The firing angle is set to be greater than $90^{\circ}$ and less than $180^{\circ}$ and that is to force the bridge converter to operate in the "inverter mode of operation".

As to the performance to the active power filter, one can examine columns 4 and 8 of Table 3 , it is quite clear that the existence/installation of the filter has lowered the total harmonic distortion factor in the power utilities supply to very reasonable levels.

To see it much better, Figure $\mathbf{3}$ visualizes one cycle steady state time-varying waveforms of the power utilities currents, the converter current (i.e current entering the bridge converter from its $A C$ side), and the current generated by the active power filter. The curves refereed with the text arrow (1) are obtained when using the active power filter while the ones refereed with the text arrow (2) are obtained in the absence of the active power filter. The text arrow (3) in the right column of Figure 3 represents the current generated by the active power filter while the text arrow (4) in the same right column represents the desired/reference current which serves as an input to the hysteresis controller.

Examining the left column of Figure $\mathbf{3}$, one can clearly notice that the supply current curves, attributed with the text arrow (1), are nearly sinusoidal. This means that the active power filter has performed its tasks correctly. The absence of the active power filter results with the curves attributed with the text arrow (2). Such curves are quite distorted especially in the case of the $6 \mathrm{~m} / \mathrm{s}$ wind speed.

Examining the curves shown in the right column of Figure 3, one can notice that the current generated by the active power filter, current attributed the text arrow (3), follows-up adequately the reference current attributed the text arrow (4).

\section{CONCLUSION}

Interconnecting a wind driven a separately excited DC machine with a power utilities grid has been investigated in this paper. The interconnection of a wind driven DC generator has been done through the installation of a controlled single full wave bridge rectifier/converter. The converter has been operated in the "inverter mode of operation". To get rid of the harmonic currents, that are expected to be generated by the used bridge converter, a shunt active power filter 


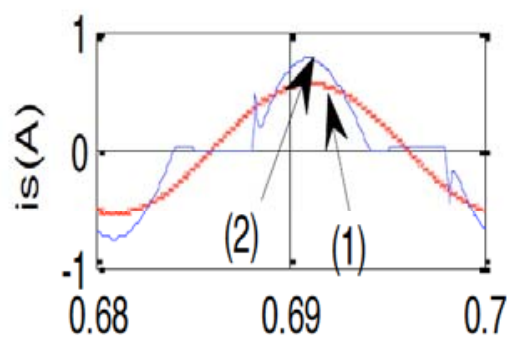

(a)

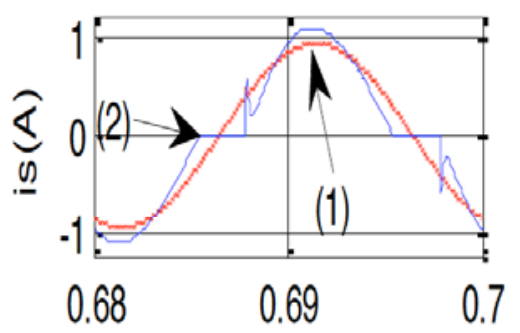

(d)

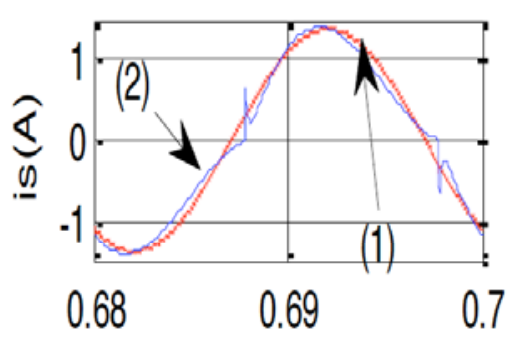

(g)

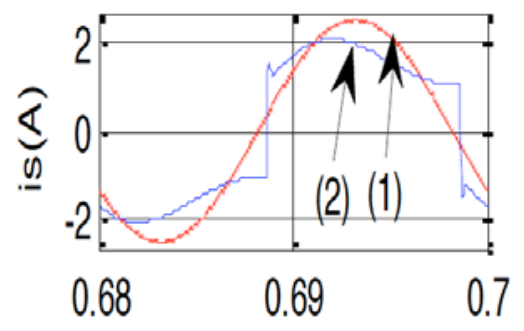

(i)

Time (s)

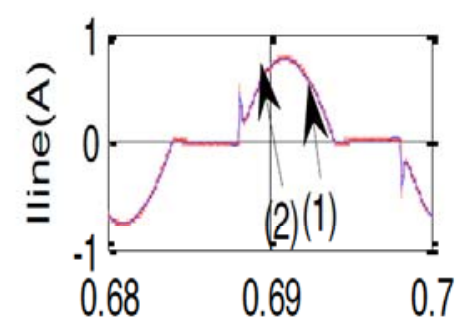

(b)

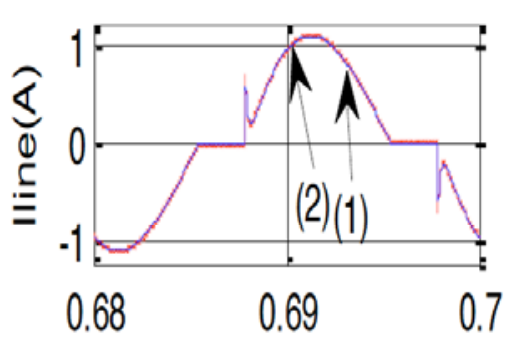

(e)

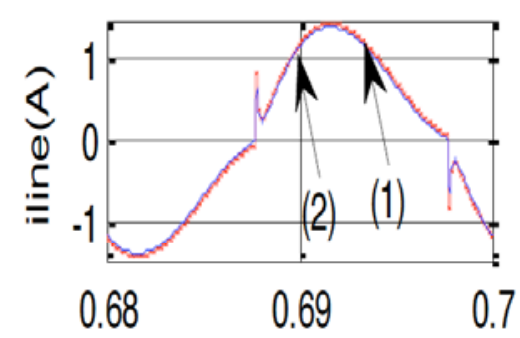

(h)

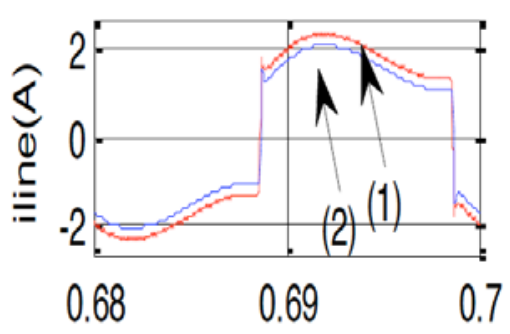

$(k)$

Time $(s)$

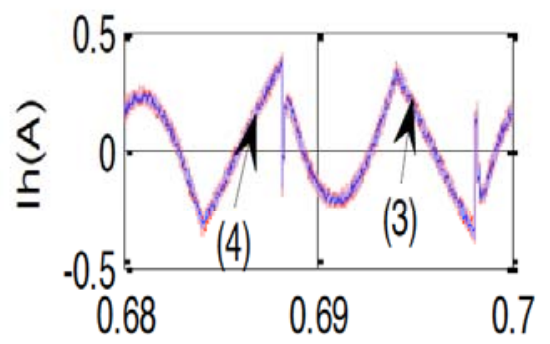

(c)

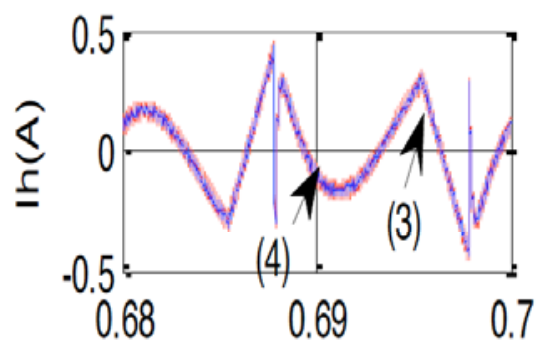

(f)

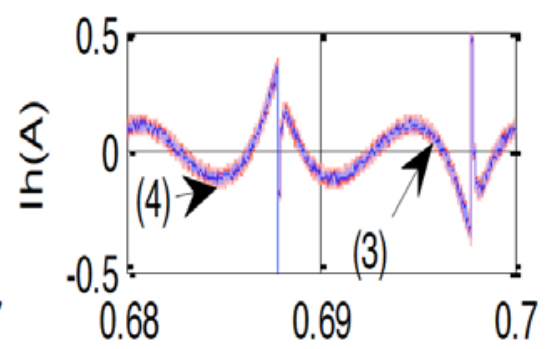

(i)

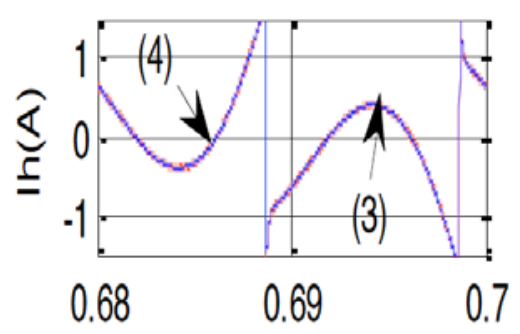

(I)

Time $(s)$

Figure 3: Simulation Results: a) supply currents under $3 \mathrm{~m} / \mathrm{s}$ wind speed, b) converter currents under $3 \mathrm{~m} / \mathrm{s}$ wind speed, c) active power filter current under $3 \mathrm{~m} / \mathrm{s}$ wind speed, d) supply currents under $4 \mathrm{~m} / \mathrm{s}$ wind speed, e) converter currents under 4 $\mathrm{m} / \mathrm{s}$ wind speed, f) active power filter current under $4 \mathrm{~m} / \mathrm{s}$ wind speed, g) supply currents under $5 \mathrm{~m} / \mathrm{s}$ wind speed, h) converter currents under $5 \mathrm{~m} / \mathrm{s}$ wind speed, i) active power filter current under $5 \mathrm{~m} / \mathrm{s}$ wind speed, j) supply currents under $6 \mathrm{~m} / \mathrm{s}$ wind speed, k) converter currents under $6 \mathrm{~m} / \mathrm{s}$ wind speed, I) active power filter current under $6 \mathrm{~m} / \mathrm{s}$ wind speed.

has been installed between the AC supply and the converter.

The performance of the overall installation has been tested through computer simulations. Maximum powers are nearly extracted from the wind driven DC machine under certain pretended wind speeds. A nearly pure sinusoid characteristic has been also observed in the AC grid current (i.e supply current) under the previous pretended wind speeds.

The proposed technique of interconnection of the renewable energy source with the power utilities grid, offers certain merits like: no worries about the 
synchronization of the AC grid with the wind generator, no need for storage units, and no harmonic currents penetrate into the AC grid when using the shunt active power filter.

\section{REFERENCES}

[1] Chedid R, Akiki H, Rahman S. A Decision Support Technique for the Design of Hybrid Solar-Wind Power Systems. IEEE Trans Energy Conver 1998; 13: 76-83. http://dx.doi.org/10.1109/60.658207

[2] Biczel P, Koniak M. Design of Power Plant Capacity in DC Hybrid System and Microgrid, Proceedings of the Fourth International Conference On Ecological Vehicles and Renewable Energies (EVER09), Monte Carlo, Monaco, March 26-29 2009.
[3] IEEE Standard for Interconnecting Distributed Resources with Electric Power Systems. Standard IEEE 1547-2003, 2003.

[4] Taleb M, Salman H, Jumaa H, Al-Mukharreq H. Performance of a Hybrid Wind-Grid-Load Energy System. J Technol Innovat Renewable Energy 2012; 1: 48-52.

[5] Rahmani S, Al-Haddad K, Kanaan HY. A comparative study of shunt hybrid and shunt active power filters for singlephase applications: Simulation and experimental validation. Math Comput Simulat 2006; 71: 345-59. http://dx.doi.org/10.1016/i.matcom.2006.02.018

[6] Heier S. Grid Integration of Wind Energy Conversion Systems, John Wiley \& Sons Company 1998.

[7] Taleb M. Optimal Operation of a Wind Driven System. J King Saud Univ, \{Engineering Sciences\} 2004; 16: 229-52. 